\title{
ANL/ETfep-85044 CONF-950793--1
}

\section{DEVELOPMENT OF A MILLIMETER-WAVE SENSOR FOR ENVIRONMENTAL MONITORING*}

\author{
Nachappa Gopalsami, Sasan Bakhtiari, and Apostolos C. Raptis \\ Energy Technology Division \\ ARGONNE NATIONAL LABORATORY \\ Argonne, IL 60439
}

June 1995

\begin{abstract}
The submitted manuscript has been authored by a contractor of the U. S. Government under contract No. W-31-109-ENG-38. Accordingly, the U.S. Government retains a nonexclusive, royalty-free license to publish or reproduce the published form of this contribution, or allow others to do so, for U. S. Government purposes.
\end{abstract}

\section{DISCLAIMER}

\begin{abstract}
This report was prepared as an account of work sponsored by an agency of the United States Government. Neither the United States Government nor any agency thereof, nor any of their employees, makes any warranty, express or implied, or assumes any legal liability or responsibility for the accuracy, completeness, or usefulness of any information, apparatus, product, or process disclosed, or represents that its use would not infringe privately owned rights. Reference herein to any specific commercial product, process, or service by trade name, trademark, manufacturer, or otherwise does not necessarily constitute or imply its endorsement, recommendation, or favoring by the United States Government or any agency thereof. The views and opinions of authors expressed herein do not necessarily state or reflect those of the United States Government or any agency thereof.
\end{abstract}

Invited paper to be presented at the SPIE's 40th Annual Meeting, International Symposium on Optical Science, Engineering and Instrumentation, to be held in San Diego, California, July 9-14, 1995.

*This work was supported by the U. S. Department of Energy, Laboratory Directed Research and Development Funds, under Contract W-31-109-Eng-39. 


\section{DISCLAIMER}

Portions of this document may be illegible in electronic image products. Images are produced from the best available original document. 
Development of a millimeter-wave sensor for environmental monitoring

N. Gopalsami, S. Bakhtiari, and A. C. Raptis

Energy Technology Division

Argonne National Laboratory, Argonne, Illinois 60439

\begin{abstract}
A millimeter-wave (mm-wave) sensor in the frequency range of $225-315 \mathrm{GHz}$ range is being developed for continuous emission monitoring of airborne effluents from industrial sites with applicability to environmental compliance monitoring and process control. Detection of chemical species is based on measuring the molecular rotational energy transitions at mm-wave frequencies. The mm-wave technique offers better transmission properties compared to optics in harsh industrial environments such as those with smoke, dust, aerosols, and steam as well as in adverse atmospheric conditions. The laboratory measurements indicate that polar molecules can be measured with a sensitivity of tens of parts-per-million-meter using this technology. Proof of principle of the open-path system has been tested by releasing and detecting innocuous chemicals in the open air. It uses a monostatic radar configuration with transmitter and receiver on one side and a corner cube on the other side of the plume to be measured. A wide-band swept frequency mm-wave signal is transmitted through the plume and the return signal from the corner cube is detected by a hot-electron-bolometer. Absorption spectra of the plume gases are measured by comparing the return signals with and without the plume in the beam path. Using a novel signal processing technique based on deconvolution, high specificity of detection has been shown for resolving individual chemicals from a mixture. This technology is applicable for real-time measurement of a suite of airborne gases/vapors emitted from vents and stacks of process industries. A prototype sensor is being
\end{abstract}


developed for wide-area monitoring of industrial sites and in-place monitoring of stack gases.

Key Words: Millimeter Waves, spectroscopy, effluent detection, chemical analysis.

\section{INTRODUCTION}

The Clean Air Act Amendments of 1990 dictate many new regulations, including the need for continuous-emissions-monitoring devices. ${ }^{1}$ The present availability of chemical sensors for stack gas or effluent monitoring is very limited; most are speciesspecific and point-type sensors. ${ }^{2}$ There is a need for standoff, wide-area monitoring of chemicals that are released from stacks and vents of process plants. Such sensors will not only demonstrate environmental compliance but also will monitor process conditions and safety.

The Fourier-transform infrared (FTIR) technique is one of the approaches being explored for standoff monitoring of stack-gases. ${ }^{3}$ While this technique mainly shows vibrational bands of molecular functional groups, the mm-wave spectra are generally unique to a molecule and often simpler to interpret because there are no complications with respect to vibrational or electronic transitions. Additionally, there is less interference from water vapor and other atmospheric species because of broad atmospheric windows in the mm range, centered on 94,140 , and $225 \mathrm{GHz}$. Unlike in FTIR, there are no moving parts so the mm-wave sensor is less affected by vibration, and deployment and maintenance are easier. Millimeter-wave techniques can be used in smoky and dusty environments, are less affected by cloud conditions, and can provide longer detection ranges. 
Millimeter-wave spectroscopy is an established laboratory technique for determining the structure and dynamics of molecules in the gas or vapor phase. ${ }^{4}$ Polar molecules selectively absorb electromagnetic radiation of specific wavelengths in the millimeter and centimeter regions in accordance with their rotational energy transitions. Millimeter-wave spectral lines are narrow and highly resolvable under low pressures $(<1$ torr). Remote monitoring of chemicals in the air, however, requires that measurements be made at ambient atmospheric pressure. The increased pressure has two effects on the rotational line: (a) it reduces the detection peak and (b) it broadens the spectral line. As a result, detection sensitivity and chemical selectivity suffer. But these problems can be mitigated by using high-frequency mm waves with wide bandwidths. Detection sensitivity increases in general with the square of the frequency, and the number of resolution lines (chemical selectivity) increases with the wide bandwidth that is practical with high-frequency $\mathrm{mm}$ waves.

Critical to the feasibility of the mm-wave technique is determination of detection sensitivities of industrial chemicals as well as its selectivity in a multicomponent mixture. This paper presents results of mm-wave spectral properties of chemicals in the 225-315 $\mathrm{GHz}$ frequency range at ambient pressure, followed by proof of principle tests of the open-path monitoring using a monostatic swept-frequency radar system. Finally, a deconvolution procedure is outlined for determination of individual chemicals in a plume.

\section{MILLIMETER-WAVE SPECTRAL MEASUREMENTS}

Millimeter-wave sensitivities of several organic and inorganic chemicals have been tested in our laboratory in the $225-315 \mathrm{GHz}$ frequency range. For analytical purposes, the molecules may be classified into two groups: (a) those with spectral lines spaced far apart in the frequency domain and consequently resolvable even when pressure- 
broadened and (b) those with dense lines that are not individually resolvable. Simple molecules such as $\mathrm{H}_{2} \mathrm{~S}, \mathrm{NO}$, and $\mathrm{CO}$ belong to the first group, and complex and heavy molecules such as $\mathrm{SO}_{2}$ and most organic chemicals belong to the second group.

\subsection{Experimental measurements}

Figure 1 is a schematic diagram of an active mm-wave spectrometer system built for absorption measurements in the frequency range of $225-315 \mathrm{GHz}$. A backward-wave oscillator (Micro-Now model 715R) is used as a mm-wave source and can be swept over a frequency range of $75-110 \mathrm{GHz}$, providing a power output exceeding $25 \mathrm{~mW}$. An absorption-type wavemeter (Hughes) is used to calibrate the frequencies.

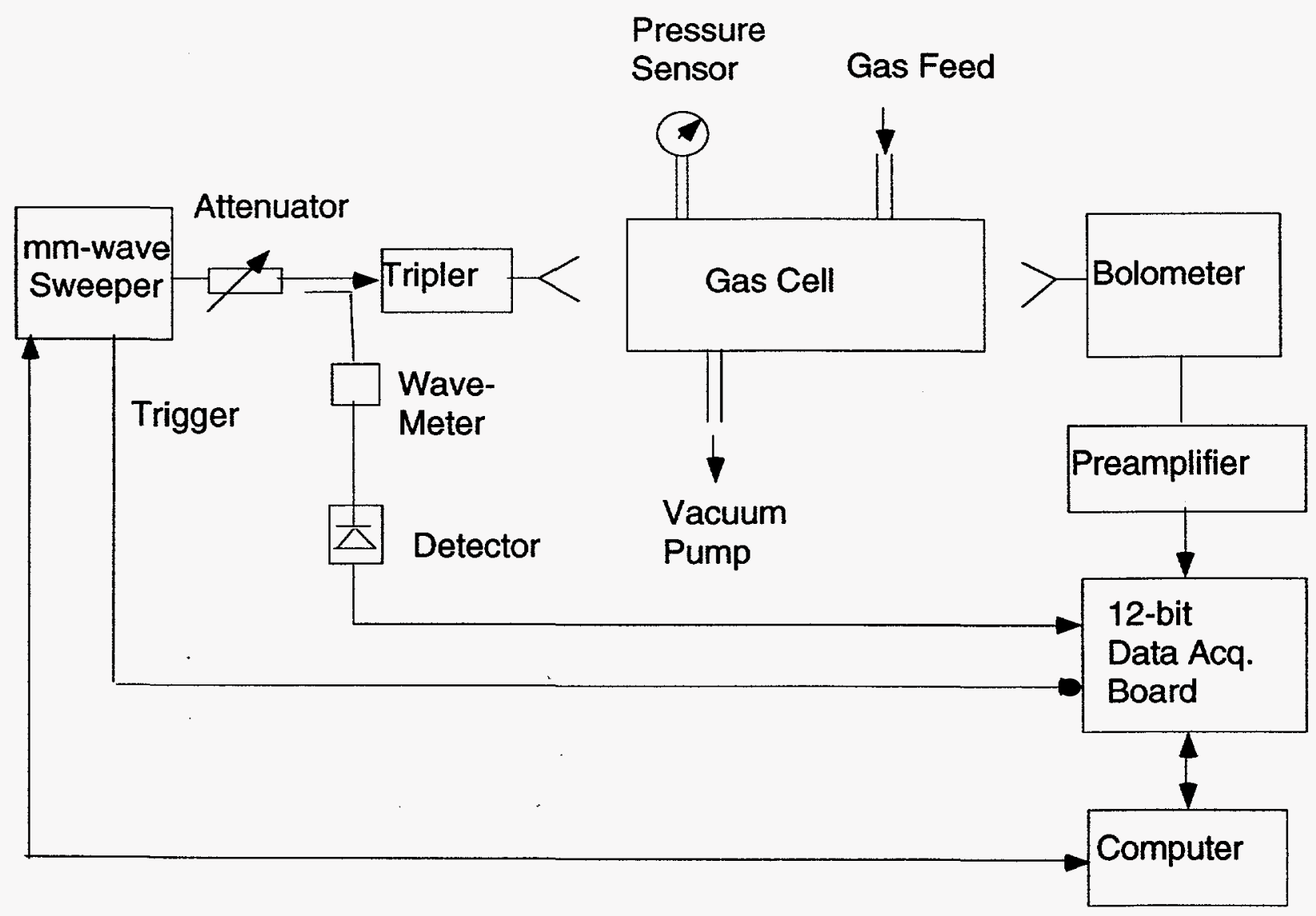

Fig.1. Schematic diagram of mm-wave spectrometer in $225-315 \mathrm{GHz}$ range. 
The swept-frequency output of the sweeper is frequency-multiplied (tripled) by using Schottky varactor diodes. ${ }^{5}$ Two wideband fixed-tuned triplers (Millitech Models FTT01 and FTT03) are used separately in the input frequency ranges of $75-90 \mathrm{GHz}$ and $90-105 \mathrm{GHz}$, with power efficiencies of 2 and $4 \%$, respectively. The frequency-tripled millimeter waves are transmitted into a gas cell by an antenna, through appropriate waveguides. The gas cell consists of a glass pipe, $0.15 \mathrm{~m}$ in diameter and $1.4-\mathrm{m}$ in length, and is fitted with vacuum and gas feed lines. The gas-cell windows are made of $0.64-\mathrm{cm}$ thick quartz plates, which provide good mm-wave transmission and adequate stiffness to pressure changes. A vacuum pump is used to control the pressure in the gas cell, which is monitored by a four-decade capacitance manometer (MKS Instruments Baratron Pressure Sensor).

The millimeter waves, after passing through the gas cell, are received by a hotelectron bolometer (Infrared Laboratory), which is liquid He cooled. This is a highly sensitive, wideband detector suitable for detecting low-power radiation. The detector provides an output voltage in the video-frequency range, proportional to the input power. A preamplifier (SR 510) with filtering capabilities is used to increase the detector output level. Selection of filter bandwidth depends on detector noise and the sweep rate (sweep width/sweep time) of the source. Preamplifier output is acquired in a PC 386 computer equipped with a 12-bit digitizer board.

The swept-frequency traces are acquired with and without the gas to be tested in the cell. Let $\mathrm{P}_{0}(v)$ be the output power of the transmitter antenna as a function of frequency, and $P_{1}(v)$ and $P_{2}(v)$ the power measured by the detector without and with the gas, respectively; then

$$
\mathrm{P}_{1}(v)=\mathrm{P}_{0}(v) \mathrm{T}
$$




$$
\mathrm{P}_{2}(v)=\mathrm{P}_{0}(v) \mathrm{T} \exp [-\alpha(v) \ell]
$$

where $\mathrm{T}$ is the transmission coefficient between the transmitter antenna and receiver with no absorbing gas in the cell, $\alpha(v)$ is the absorption coefficient of the gas at frequency $v$, and $\ell$ is the length of the cell. The normalized spectral absorption $\mathrm{S}(v)$ of the gas is given by

$$
S(v)=\frac{P_{1}(v)-P_{2}(v)}{P_{1}(v)}=\{1-\exp [-\alpha(v) \ell]\}
$$

Molecular spectral measurements were made at a partial pressure of 1.5 torr of the target chemical mixed with 758.5 torr of nitrogen. Frequency sweeps were made in two steps: $224.809-272.397 \mathrm{GHz}$ and $272.55-320.897 \mathrm{GHz}$ and then combined into a single plot. A linear ramp with $2 \mathrm{~s}$ period was used to sweep each of the frequency bands, and the swept frequency data were filtered by a $10-\mathrm{Hz}$ low-pass filter. The sweep frequencies were calibrated by using a absorption-type wavemeter off-line. The percent absorption was calculated using (3) in which the $P_{1}(v)$ trace was obtained by filling the gas cell with nitrogen to 760 torr. This reduced possible error due to window deflections under different pressures.

The experimental measurements were compared with theoretical simulation that used Lorentzian line-shape function to account for the effect of pressure broadening. 6 The Jet Propulsion Laboratory (JPL) has compiled a list of spectral lines of many chemicals. ${ }^{7}$ The JPL catalog contains the spectral line frequencies and integrated absorption peaks of molecules at 1 torr pressure. The combined pressure-broadened 
absorption coefficient $\alpha(v)$ of multiple transition lines of a molecule at a pressure $p$ may be derived as

$$
\alpha(v)=\sum_{i=1}^{m} \frac{\alpha_{\text {int,i }} \Delta v}{\left(v-v_{i}\right)^{2}+(\Delta v)^{2}}
$$

where $\alpha_{\mathrm{int}, \mathrm{i}}$ is the integrated absorption peak of transition line $\mathrm{i}$ for a known low pressure, say 1 torr; $\Delta v$ is the line width at the desired pressure $\mathrm{p}$; and $\mathrm{m}$ is the number of transition lines in the frequency range of interest. If $\Delta v$ is known or can be measured, the pressure-broadened spectral lines may be simulated by using the JPL data available for $\alpha_{\text {int,i }}$ and $v_{i}$. Although the line width will vary somewhat with respect to transition states, we neglect this effect in the simulation.

Figures 2 and 3 show the simulated and measured absorption spectra of $\mathrm{H}_{2} \mathrm{~S}$ and $\mathrm{SO}_{2}$, respectively. Agreement is generally good between the simulated and measured absorption spectra. Major factors contributing to variations between the simulated and measured spectra are inadequacy of the Lorentzian model at high pressures, frequency jitters of the free-running sweeper, and use of a filter for smoothing the experimental data which cause a slight shifting of the peak location as well as a reduction of the peak height. 


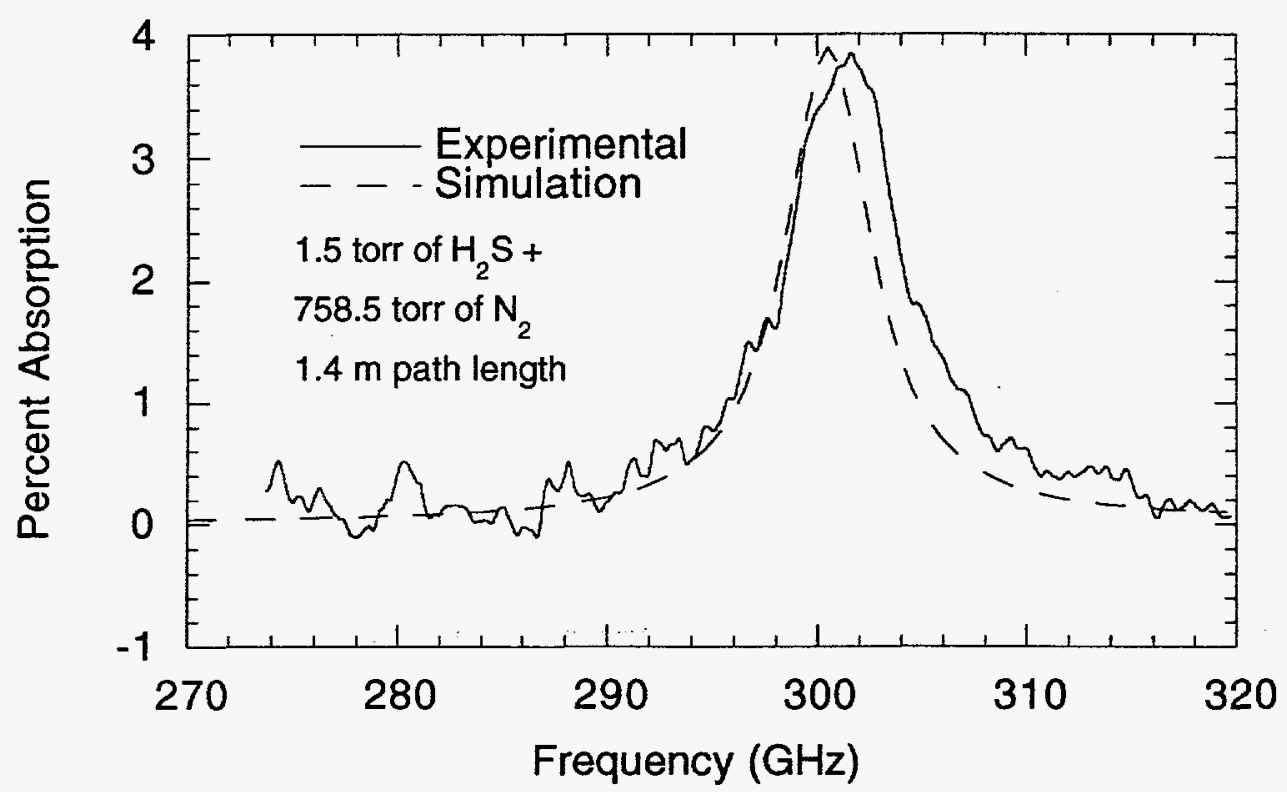

Fig. 2. Absorption line of $\mathrm{H}_{2} \mathrm{~S}$.

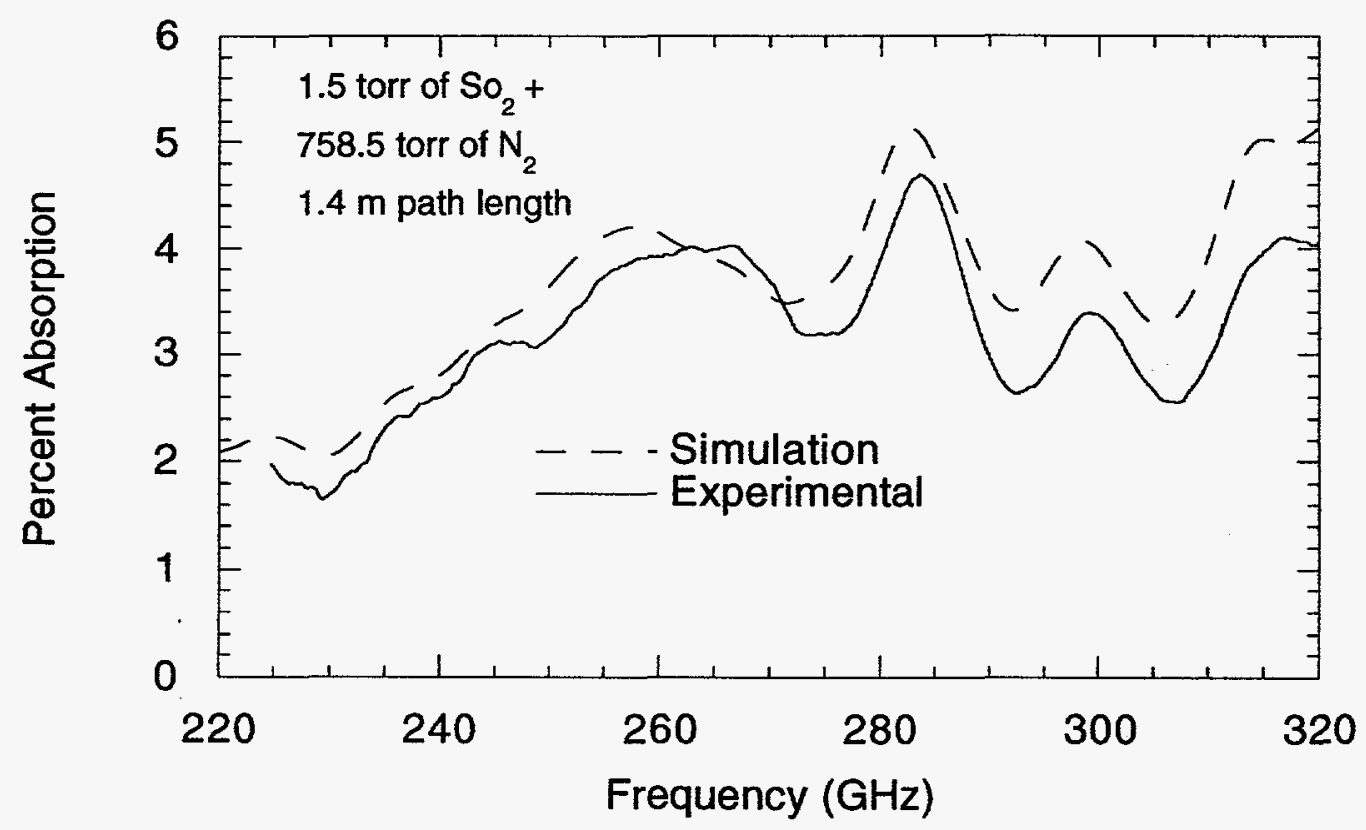

Fig. 3. Absorption spectra of $\mathrm{SO}_{2}$.

\subsection{Open-path measurements}


The laboratory mm-wave spectrometer in Fig. 1 can be extended to provide monostatic swept-frequency radar measurements. Figure 4 is a schematic diagram of the radar system that was assembled on a cart. The transmitter and receiver components are identical to those in Fig. 1. The mm-wave radiation was transmitted through a plume; a corner cube of $0.15-\mathrm{m}$ size on the far side of the plume returned the radiation back to the receiver. Lenses were used to collimate and focus the mm-wave beam. A plume was created by heating $\mathrm{D}_{2} \mathrm{O}$ in a beaker and releasing the $\mathrm{D}_{2} \mathrm{O}$ vapor in the path of the mmwave beam.

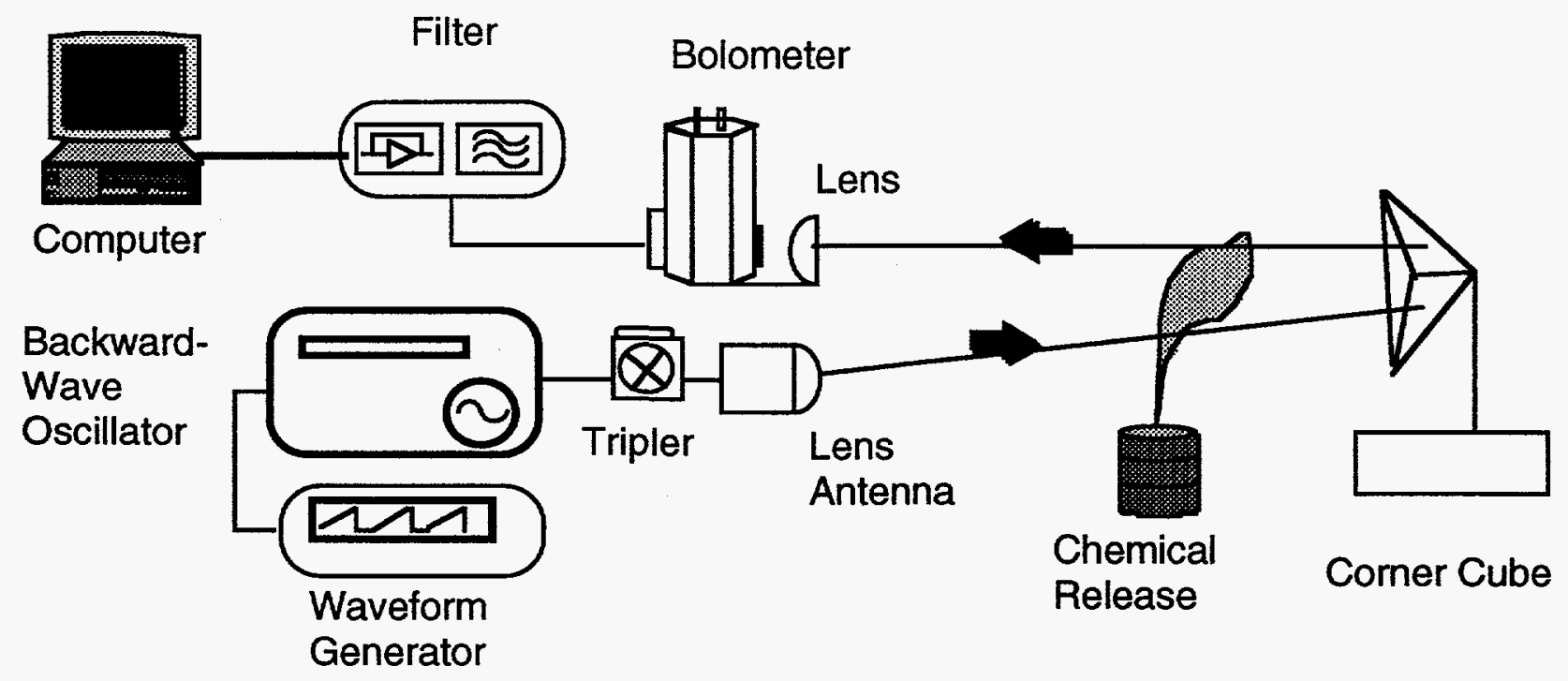

Fig. 4. Schematic diagram of open-path measurement setup.

Figure 5 gives the measurement results as the release rate decreased with time. The absorption peak of $\mathrm{D}_{2} \mathrm{O}$ decreased with the release rate. For comparison, the gas cell absorption data taken with the setup in Fig. 1 is shown; it is in good agreement with the open-path data. The effect of atmospheric fluctuations on the measurements was insignificant in the short radar ranges (up to $10.7 \mathrm{~m}$ ) we used. Further work is underway to test the atmospheric effects such as scintillation on long range open-path spectral measurements. 


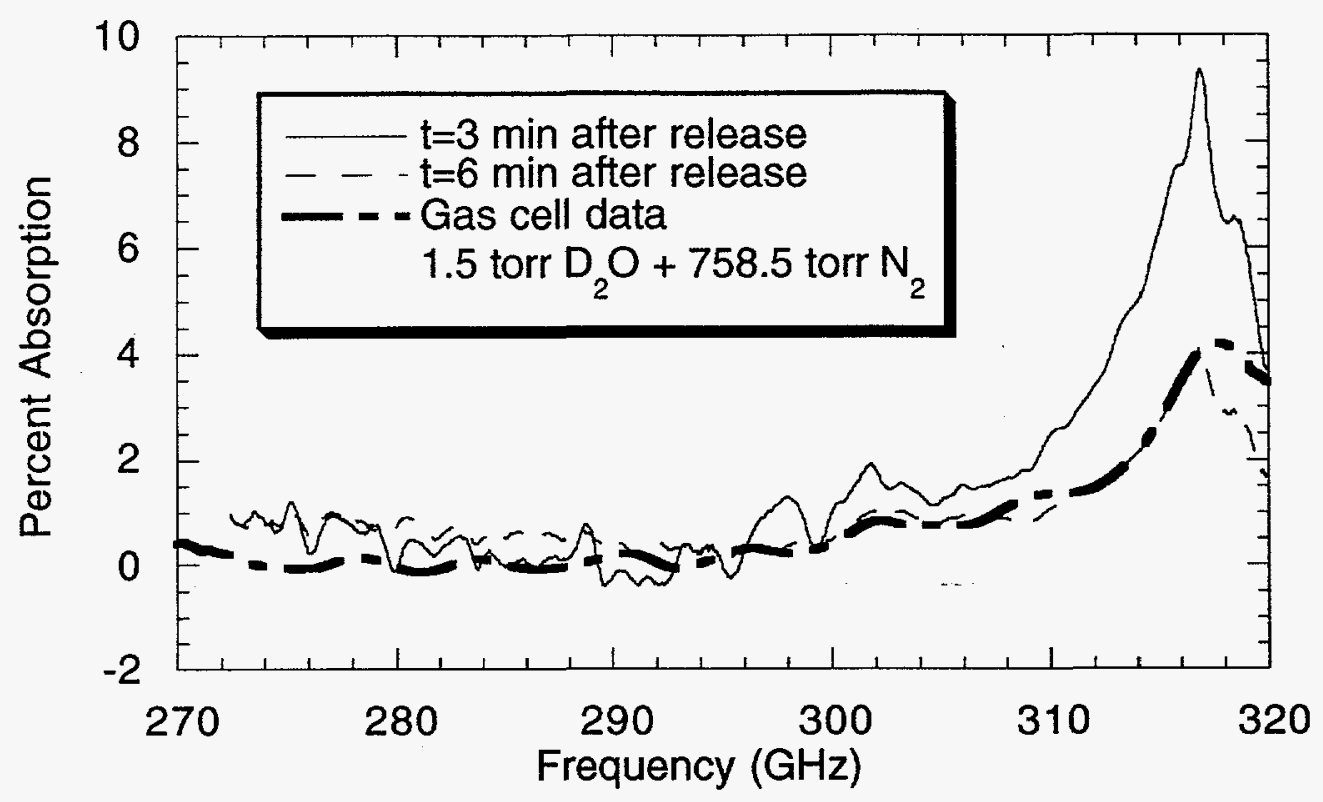

Fig. 5. Detection of $\mathrm{D}_{2} \mathrm{O}$ plume released in open air.

\section{DECONVOLUTION OF MULTICHEMICAL SPECTRA}

Although the absorption properties of molecules in the $\mathrm{mm}$ range are distinctly different at low pressures, the pressure-broadened spectral lines can overlap causing difficulties in the mixture analysis. Because a sensor must detect and quantify individual chemicals in a multicomponent mixture, the selectivity of the technique is important. A new approach based on deconvolution has been developed which offers high selectivity.

Figure 6 shows the deconvolution procedure wherein the relationship between the low-pressure and pressure-broadened spectra are first obtained in the form of a filter. The pressure-broadened spectra of a chemical may be viewed as the filtered response of its low-pressure spectra. Depending on their line locations and line widths, the filter characteristics will differ with each chemical. Inverse filtering, or deconvolution, is performed on the unknown composite spectra to determine the corresponding low- 
pressure spectra of the desired chemical. Because the line widths of deconvolved spectra are smaller by two to three orders of magnitude than the pressure-broadened spectra, spectral specificity is dramatically improved by this process.

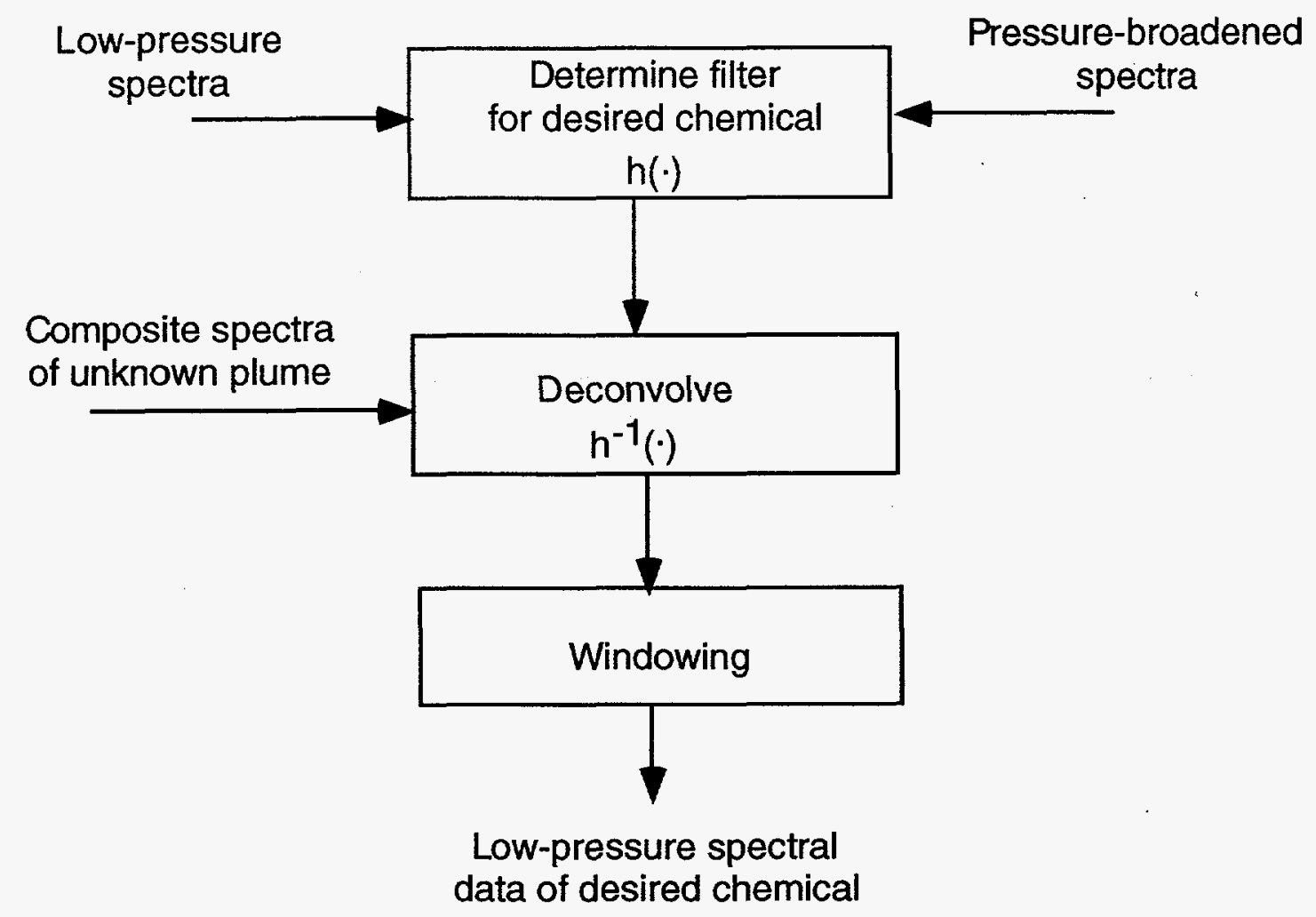

Fig. 6. Block diagram of deconvolution procedure.

The deconvolution procedure was tested with individually-measured data of three chemicals, $\mathrm{CH}_{3} \mathrm{CN}, \mathrm{CH}_{3} \mathrm{Cl}$, and $\mathrm{CH}_{2} \mathrm{Cl}_{2}$. A synthetic mixture data was created by adding individually measured spectra of the three chemicals with desired concentrations. Figure 7 gives the combined spectra of the synthetic mixture with partial pressures of 200 mtorr of $\mathrm{CH}_{3} \mathrm{CN}, 400$ mtorr of $\mathrm{CH}_{3} \mathrm{Cl}$ and 600 mtorr of $\mathrm{CH}_{2} \mathrm{Cl}_{2}$ mixed with nitrogen to a total of one atmosphere. Suppose one is interested in estimating the concentration of $\mathrm{CH}_{3} \mathrm{Cl}$ in the mixture. Figure 8 gives the low- and high-pressure spectra of $\mathrm{CH}_{3} \mathrm{Cl}$, from which the deconvolution filter is designed. The deconvolved $\mathrm{CH}_{3} \mathrm{Cl}$ spectra from the mixture data is given in Fig. 9. Line locations and line widths are identical to those in the low- 
pressure measurement data. More important, the spectra of the other two chemicals are suppressed in the final results. Thus, the deconvolution technique results in highly resolved spectral lines.

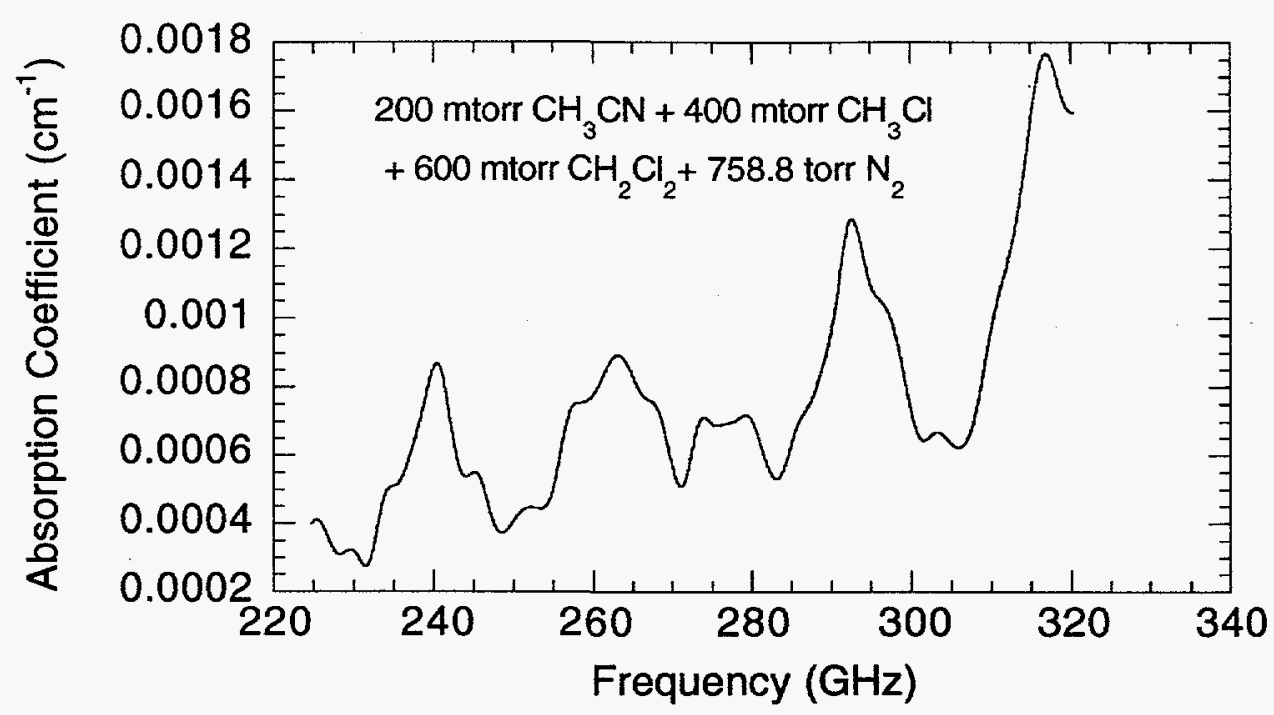

Fig. 7. Absorption spectra of synthetic mixture of three chemicals.

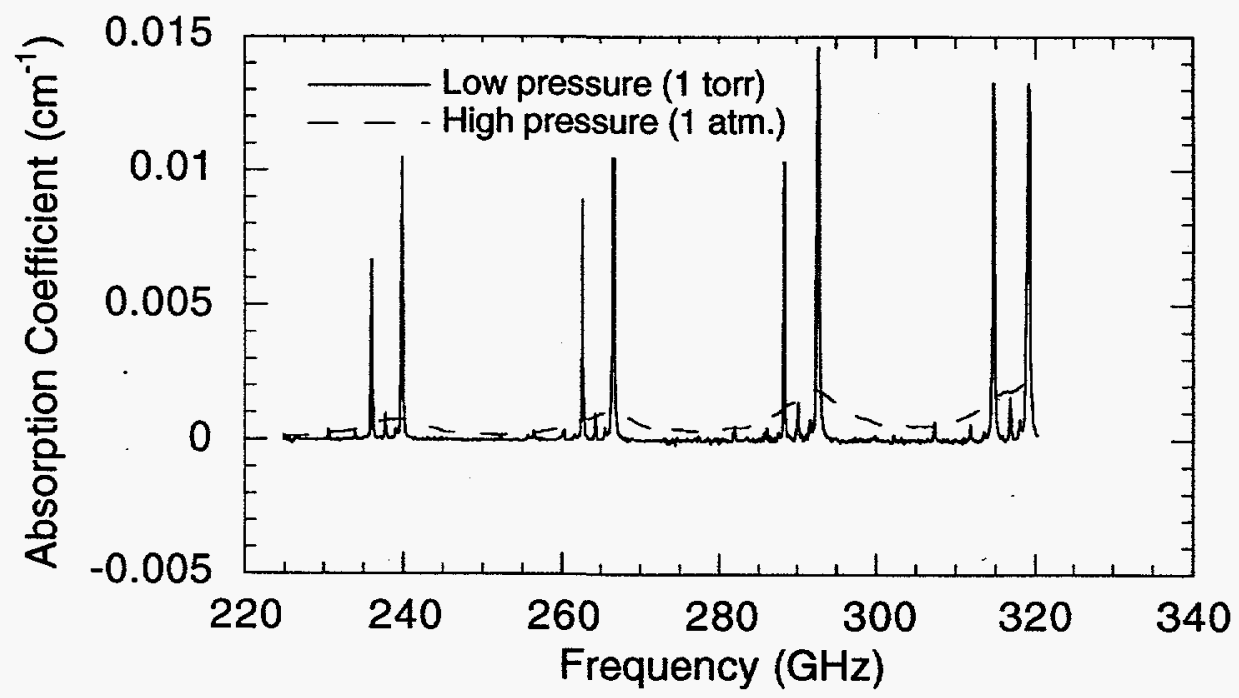

Fig. 8. Low- and high-pressure spectra of $\mathrm{CH}_{3} \mathrm{Cl}$ at 1 torr partial pressure. 


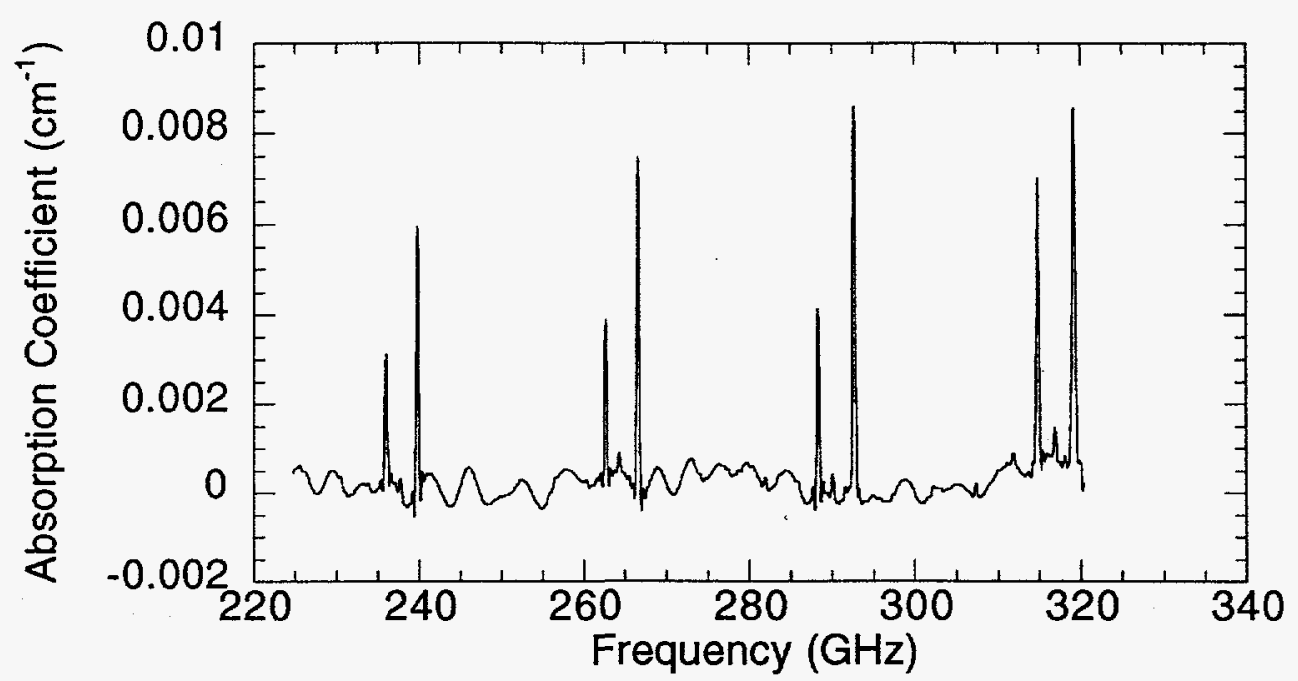

Fig. 9. Deconvolved spectra of $\mathrm{CH}_{3} \mathrm{Cl}$ at 0.4 torr partial pressure.

The above deconvolution procedure does not assume any a priori knowledge of the plume constituents. It gives only qualitative estimate of the amount of a desired chemical in an unknown plume. This is because the contribution of a particular deconvolution filter due to the rest of the chemicals is ignored. If the chemical composition of the plume is known, the deconvolution method can be modified to provide quantitative estimates. The deconvolution operation for a mixture of $\mathrm{N}$ chemicals may be stated as,

$$
h_{i}(t) \otimes \sum_{i=1}^{N}\left[w_{i} c_{i}(t)\right]=h_{i}(t) \otimes m(t)
$$

where $m(t)$ is the spectral data of the mixture, in which the spectral frequency is treated as a time-domain variable $t$, $i$ denotes chemical number, $h_{i}(t)$ is the inverse filter for chemical $i, c_{i}(t)$ its pressure-broadened spectra, $w_{i}$, its concentration, and $\otimes$ is the convolution operator. By evaluating (5) at $\mathrm{t}=\mathrm{t} \mathrm{j}$ where chemical $\mathrm{i}$ has a spectral peak, one 
can obtain a set of $M(\geq N)$ simultaneous equations from which the individual chemical concentrations $W_{i}$ can be determined.

To evaluate the quantitative estimation technique, a synthetic mixture data was created by adding a linearly weighted set of simulated spectra from 25 chemicals. Table I gives the list of 25 chemicals; the concentrations in partial pressures of first five chemicals were $0.7,0.35,0.9,0.4$, and 0.5 torr and that of the rest were 0 torr. The deconvolution technique estimated the concentrations accurately as in Table I. Although the deconvolution operation is generally not robust on noise corrupted data, ${ }^{8}$ the use of multiple spectra peaks of molecules in (5) can be used to formulate a well-posed problem. Further work is required to evaluate the technique on real mixture data.

\section{CONCLUSIONS}

The mm-wave spectral properties of chemicals were tested in the $225-315 \mathrm{GHz}$ frequency range with application to standoff monitoring of airborne effluents. The pressure-broadened molecular lines were measured in a gas cell with a broadband sweptfrequency source and hot-electron-bolometer detector. The spectral line widths of molecules at ambient atmospheric pressure are generally about $4 \mathrm{GHz}$ at half-width, halfheight. Interestingly, complex and heavy molecules yield characteristic mm-wave spectral signatures under pressure broadening, so the technique can be used for detection of both simple and complex molecules.

Proof of principle of the technique using a monostatic swept-frequency radar technique was tested by releasing $\mathrm{D}_{2} \mathrm{O}$ in open air. The tests showed the feasibility of standoff detection of airborne chemicals by the mm-wave technique. Further work is underway to test the system against different ground targets (instead of using a corner cube), with the goal of deploying such a system in an aircraft for wide area monitoring. 
A deconvolution procedure has been devised for estimation of the individual chemical concentrations in a multicomponent mixture. Based on design of a filter that relates the low- and pressure-broadened spectral lines of a chemical, the deconvolution procedure estimates the low-pressure lines of that chemical from the composite spectral data of the mixture. Because the low-pressure lines are narrower by two to three orders of magnitude than the pressure-broadened lines, the deconvolution method showed dramatic improvement in chemical resolvability.

\section{ACKNOWLEDGMENTS}

The authors wish to thank Dr. S. L. Dieckman for helpful discussions, Mr. Ron Lanham for building the mm-wave facility, and Ms. Marinda Graham for her assistane with the deconvolution algorithm. This work is supported by the U.S. Department of Energy, Office of Nonproliferation and National Security, Office of Research and Development and Laboratory Directed Research and Development, under Contract W-31-109-ENG-38.

\section{REFERENCES}

1. G. J. Blickley, "Emission regulations require new breed of analyzers," Control Engineering , pp. 48-49, May 1993.

2. J. Fraden, AIP Handbook of Modern Sensors, American Institute of Physics, New York, 1993.

3. J. T. Cronin, "Stack-gas monitoring using FT-IR spectroscopy," Spectroscopy, Vol. 7, pp. 33-39, 1992.

4. W. Gordy and R. L. Cook, Microwave Molecular Spectra, John Wiley, New York, 1984. 
5. A. V. Raisanen, "Frequency multipliers for millimeter and submillimeter wavelengths," Proc. IEEE, vol.80, pp. 1842-1852, 1992.

6. G. Birnbaum, "Microwave pressure broadening," in Intermolecular Forces, J. O. Hirschfelder, ed. (Advances in Chemical Physics, Vol. 12), John Wiley, New York, 1967.

7. R. L. Poynter and H. M. Pickett, "Submillimeter, Millimeter, and Microwave Spectral Line Catalog," JPL Publication 80-23, Revision 2, 1983.

8. P. A. Jansson, (Ed.), Deconvolution with Applications in Spectroscopy, Academic Press, Orlando, 1984. 
Table I. Deconvolution results of 25 chemicals

\begin{tabular}{|c|c|c|c|c|c|}
\hline Chemical & $\begin{array}{c}\text { Concentration } \\
\text { (torr) }\end{array}$ & Chemical & $\begin{array}{c}\text { Concentration } \\
\text { (torr) }\end{array}$ & Chemical & $\begin{array}{c}\text { Concentration } \\
\text { (torr) }\end{array}$ \\
\hline $\mathrm{CH}_{3} \mathrm{CN}$ & 0.7000 & $\mathrm{ClO}$ & $1.34 \mathrm{e}-12$ & $\mathrm{HNCO}$ & $-1.1 \mathrm{e}-11$ \\
\hline OCS & 0.3500 & $\mathrm{H}_{2} \mathrm{CO}$ & $1.8 \mathrm{e}-12$ & $\mathrm{C}_{2} \mathrm{H}_{5} \mathrm{OH}$ & $1.2 \mathrm{e}-11$ \\
\hline $\mathrm{HCN}$ & 0.9000 & $\mathrm{HC}_{3} \mathrm{~N}$ & $-1.63 e-14$ & $\mathrm{CH}_{3} \mathrm{Cl}^{35}$ & $-6.74 \mathrm{e}-13$ \\
\hline $\mathrm{H}_{2} \mathrm{~S}$ & 0.4000 & $\mathrm{PH}_{3}$ & $-1.2 \mathrm{e}-10$ & $\mathrm{NO}_{2}$ & $6.9 \mathrm{e}-11$ \\
\hline $\mathrm{SO}_{2}$ & 0.5000 & $\mathrm{CH}_{3} \mathrm{CN}^{15}$ & $-1.1 \mathrm{e}-13$ & $\mathrm{NH}_{3}$ & $1.34 \mathrm{e}-6$ \\
\hline $\mathrm{CH}_{3} \mathrm{Cl}^{37}$ & $-4.6 \mathrm{e}-14$ & $\mathrm{HNC}^{13} \mathrm{O}$ & $1.5 \mathrm{e}-11$ & $\mathrm{O}_{3}$ & $1.73 \mathrm{e}-11$ \\
\hline $\mathrm{D}_{2} \mathrm{O}$ & $2.8 \mathrm{e}-11$ & $\mathrm{HNO}_{3}$ & $-2.3 e-14$ & $\mathrm{O}_{2}$ & $-5.12 \mathrm{e}-4$ \\
\hline NO & $-1.3 e-10$ & $\mathrm{H}_{2} \mathrm{O}$ & $2.52 \mathrm{e}-9$ & & \\
\hline $\mathrm{N}_{2} \mathrm{O}$ & $8.8 \mathrm{e}-12$ & HDO & $-3.42 \mathrm{e}-11$ & & \\
\hline
\end{tabular}

